\title{
Assessing the terrorist threat to the food supply: food defence, threat assessments, and the problem of vulnerability
}

\author{
Gregory R. Dalziel \\ Graduate School of Media and Governance, \\ Keio University, \\ 5322, Endo, Fujisawa, Kanagawa, 252-0882, Japan \\ E-mail: gregdl@sfc.keio.ac.jp
}

\begin{abstract}
Within a historically-informed framework utilising the related concepts of capability and intentions we identify and critically assess three core assumptions underlying the concept of food defence:

1 that there is a 'real and current' threat to the food supply chain by terrorist organisations

2 such an attack is easy to do

3 the effects of such an attack can be extrapolated from food safety incidents.

In doing so, we find that food defence is largely driven by perceptions of vulnerability, the effect of which is a misperception in threat.
\end{abstract}

Keywords: food defence; food supply; poisoning; terrorism; vulnerability; vulnerability perception; threat; threat assessments; threat perception; intention; capability; bioterrorism; CBRN; WMD.

Reference to this paper should be made as follows: Dalziel, G.R. (2011) 'Assessing the terrorist threat to the food supply: food defence, threat assessments, and the problem of vulnerability', Int. J. Food Safety, Nutrition and Public Health, Vol. 4, No. 1, pp.12-28.

Biographical notes: Gregory R. Dalziel is completing his Doctoral degree while concurrently holding a fellowship position as an Assistant Professor at the Graduate School of Media and Governance, Keio University, Japan. $\mathrm{He}$ is also a Researcher at the Global Security Research Institute (G-SEC), Keio University. He previously was an Associate Research Fellow at the Centre of Excellence for National Studies (CENS), S. Rajaratnam School of International Studies (RSIS) and Nanyang Technological University (NTU), Singapore.

\section{Introduction}

The notion that the food supply chain is at risk of intentional contamination from terrorist organisations has arisen intermittently since at least the 1970s, but became especially salient after the 9/11 attacks and 2001 US anthrax incidents. Particularly so is the worry that the food supply chain may be used as a vehicle for the dissemination of chemical or, 
worse still, biological agents. Repeated incidents of food safety breakdowns - and the damage to public health they can cause - serve for many as an example of the effects an actor with malevolent intentions could cause. A global food supply chain increases potential vulnerabilities that a terrorist organisation could conceivably exploit. This threat perception - influencing policy, research, practice, and funding - has coalesced around the term 'food defence'.

Away from the fraught emotional context and pervasive uncertainty (Ball-Rokeach, 1973) that characterised the early years of the 'global war on terror' it is time to reassess the issue of food defence and soberly examine the threat of terrorists using the food supply chain to poison the public. In this paper, we identify three major assumptions underlying food defence:

1 that there is a 'real and current' threat to the food supply chain by terrorist organisations

2 such an attack is easy to implement

3 the effects of such an attack can be extrapolated from food safety incidents.

Using a historically-informed view of the prevalence and outcomes of previous incidents as a base we frame our analysis using the concepts of capability and intention, traditional elements of threat assessments, to re-examine these three assumptions.

In doing so, we find an issue that fails to account for human agency and one in which perception of vulnerability is the predominant mode by which the threat is perceived and assessed. Allowing perceptions of vulnerability to frame a threat - what can be called a vulnerability-driven approach (Jackson and Frelinger, 2009) - can have important implications in how accurately a threat is perceived and so also in how limited resources are allocated. Previous research on threat perception highlights that a heightened sense of vulnerability can in fact increase the perception of threat, regardless of whether such a threat is at risk of occurring (Cohen, 1979; Jervis, 1976; Rousseau, 2006).

In contrast to food safety where the emphasis is on mitigating unintentional contamination, food defence posits maliciously motivated intentionality in the contamination of food. What is noteworthy about food defence is that for all the talk of terrorist threats to the food supply chain there is a surprising lack of any terrorists or terrorist activity in much of the focus on food defence. Despite this emphasis on intentionality in food defence we find most discussion centred on vulnerabilities or, much like food safety, on the effects of potential contaminants. For the food supply chain to be intentionally contaminated by terrorists they must first have the intention to do so, and the capability to make manifest such intentions.

The article is as follows. First, we explore how the food defence issue is dominated by the vulnerability-driven perspective, and the effect this may have on our perception of threat. I then explore an often forgotten Cold War relic - the threat assessment - to show how we may examine food defence using concepts such as intention and capability to get a more nuanced picture of the potential threat from terrorists to the food supply chain. Finally, I explore the three major assumptions of food defence relying on balancing the vulnerability-driven perception with both a threat assessment and a historical view of food defence incidents based on a previous study examining all food defence incidents since 1950 . 


\section{Perceptions of vulnerability and food defence: framing the threat}

\subsection{The perception of threat}

Fears of terrorists poisoning the food supply chain have periodically surfaced in the past, with reports in 1975 (Department of State, 1975) and 1986 (Miller, 1986) highlighting the recurrent nature of this threat perception on the part of some government organisations. However, in addition to the 9/11 attacks and anthrax (or 'Amerithrax') incidents in 2001, the other two drivers of the salience of this fear we suggest are:

1 the 1990s-era bio- and agro-terrorist threat perception prevalent in the USA [US

Government Accountability Office (GAO), 1999], especially the heavy, often

highly-dramatised, media reporting around this threat (Warrick, 2005)

2 predictions during the 1990s of 'new terrorism'.

This latter element posits changes in the nature of terrorism from political acts of violence carried out by groups with limited aims to groups carrying out more nihilistic acts of violence with no restrictions on the scale of violence, based on religious ideology rather than political goals (Simon, 1989; Lesser et al., 1995; Rose, 1999; Laquer, 2000; Simon and Benjamin, 2000; Rapoport, 2001; Ramakrishna and Tan, 2003; Hoffman, 2006).

However, while the 1990s bio-threat perception and fears over the changing nature of terrorists fertilised fears of foodborne bioterrorism and the like, it was $9 / 11$ and Amerithrax that allowed the food defence threat perception to grow. The pervasive uncertainty surrounding these events meant that previous discounted threats seemed far more likely. That is, because the 'unthinkable' had happened on $9 / 11$, the probability of other 'unthinkables' occurring was now higher. This type of thinking may be a common element after cases of strategic surprise (Betts, 2007). As such, perceived 'failures of imagination' seen as a causal factor in the failure to stop the 9/11 attacks from occurring meant that food defence and other 'exotic' terrorist threats became far more salient (Jackson and Frelinger, 2009).

The salience of this threat perception can especially be seen starting in 2002 with publication of a World Health Organization (WHO) report entitled Terrorist Threats to Food: Guidance for Establishing and Strengthening Prevention and Response Systems. In it they stated, "the malicious contamination of food for terrorist purposes is a real and current threat, and the deliberate contamination of food at one location could have global public health implications" [World Health Organization, (2002), p.1]. The following year saw the US Food and Drug Administration (FDA) declassify a document in which they "concluded that there is a high likelihood, over the course of a year, that a significant number of people will be affected by an act of food terrorism" (Fabi, 2003). In 2004, former US Health and Human Services (HHS) Secretary Tommy G. Thompson, in his oft-quoted resignation speech, said, "I, for the life of me, cannot understand why the terrorists have not, you know, attacked our food supply because it is so easy to do" (Branigan et al., 2004). These elements of the food defence threat perception we can identify as its core assumptions and which we assess later in the paper. 


\subsection{Narratives of the future: vulnerability-driven assessments and worst-case scenarios}

The food defence literature tends to focus either on the vulnerabilities in the food supply chain or the "harm potential of biological weapons" [Ackerman and Moran, (2004), p.6] that could be introduced into the food supply chain in an attempt to cause mass casualties. In much of the food defence (and bioterrorism) literature there is an emphasis on "identifying high-risk foods and critical control points at which contamination could be carried out" [Sobel, (2005), p.216]. This is fine in principle; however on its own it tells us little about the likelihood of an attack given the complete absence in this analysis of an attacker. The focus on agents is akin to Cold War-era analysts viewing the existence of particular weapons as evidence of an attacker's intent (Garthoff, 1978; Stech and Hoffman, 1982) except in this case one is inferring intent from the mere existence of biological and chemical weapons. We return to this issue later in the paper.

What is highlighted in these assessments are either the multitude of vulnerabilities within a global food supply chain or the negative effects that biological and/or chemical contaminants spread via the food supply chain could cause to public health. It appears that by virtue of having the property of vulnerability the food supply chain also then has the property of threatened.

In this manner, as noted earlier, much of the notion of food defence is vulnerabilitydriven. The vulnerability-driven perspective makes four assumptions:

1 sufficient capability on the part of an attacker

2 that an attacker wants to attack an identified vulnerability (intent)

3 that such an attack is successful

4 that any defence and mitigation measures fail.

Indeed, some papers that take an implicit or explicit vulnerability-driven approach simply start from the assumption that a terrorist group can defeat the security and safety measures along the food supply chain simply by merit of their determination and resourcefulness [for example, see Liu and Wein, (2008)].

The mere existence of the food supply chain along with the identification of perceived vulnerabilities that could be exploited by a hypothetical attacker with hypothetical capabilities does not mean in practice that a real-life attacker will even view the food supply chain as a preferable mode of attack (Jackson and Frelinger, 2009). In starting from a perception of vulnerability, one's analysis is directed towards finding the manner in which an actor with malevolent intentions would exploit such vulnerability; this only serves to focus on the novel features of a threat (Jackson and Frelinger, 2009), rather than whether an adversary would actually want or be able to take advantage of the perceived vulnerabilities.

While ostensibly writing about military strategy and risk Rasmussen (2006, p.67) writes that the reliance on these narratives of the future (in this case vulnerability-driven worst-case scenarios) produces planning that "focuses on how an adversary might fight rather than who that adversary might be or where he might want to engage in battle". In the case of food defence, it focuses on what the effect of biological or chemical agents would be, rather than who the adversary is and whether they have both the intent to 
actually attack the food supply chain and the capability to do so. We return to this point later in our discussion on threat assessments.

By focusing on vulnerabilities and the negative effects of differing types of contaminants food defence wholly inhabits a world of worst-case scenarios. We can see worst-case scenarios as essentially narratives of a possible negative future state (Rasmussen, 2006) and, particularly, a narrative of future failure. For example, Ambassador Benjamin Defensor, former chair of the Counter Terrorism Task Force (CTTF) of Asia-Pacific Economic Coordination (APEC), outlined such a narrative in a speech, "If terrorists were to introduce poison, disease or other contaminants to food stocks, the potential death toll would be high and widespread" (APEC, 2006).

The Cold War strategist Brodie (1978, p.83) eloquently wrote about the dangers of worst-case scenario thinking stating that once the possibility of a worst-case scenario is raised "the fact that someone has conceived of whatever proposition follows is enough to establish that it is conceivable". Such narratives, and the perceived vulnerabilities that inspire them, are practically limitless but do little in assisting the proper allocation of resources. Indeed, perceptions of vulnerability and the worst-case scenarios they engender can actually inhibit one's assessments and strategy. Before the outbreak of World War II the British state suffered from what has been termed a "Luftwaffe complex" [Cohen, (1979), p.104]. Overwhelmingly focused on their perceived vulnerability to German air attacks, the British failed to account for the technical limitations of German aircraft to conduct such long-range bombings without the use of runways in as-yet uninvaded France and Belgium. Nor, in fact, did the Germans have any sort of military doctrines on strategic bombing. British perceptions of vulnerability inhibited any focused analysis of their opponent's capability or intentions (Cohen, 1979).

\section{Threat assessments: bringing the terrorists back in}

Food defence by the very nature of its assumption of terrorism, or at the very least intentionality, means that it differs from unintentional risks of food safety outbreaks or natural disasters; in these latter cases we cannot measure intentionality and so identifying vulnerabilities may be useful (Hope, 2004, 2005). The separate existence of terrorism, biological or chemical agents, and the food supply chain in and of themselves does not constitute a threat to public health. Food defence assumes that terrorists can intentionally cause harm to public health via the food supply chain. In this case then, what is crucially missing from most food defence literature is any clear appreciation or assessment of the presumed threat. That is, who has the intent to cause mass harm via the food supply chain and do these individuals have the capability to manifest their intent?

Threat assessments are criticised as inadequate for dealing with modern-day threats to the state while too often being 'unsystematic', 'notoriously faulty' and prone to distortion or 'political manipulation' [Mandel, (2008), pp.49-51]. Here though we find confusion between the identification or perception of threat and the assessment of to what degree a particular perceived threat is likely to occur or how damaging such a threat may be if it occurs. The issue of why some things are identified as threats and others are not is beyond the scope of this paper [see Jervis, (1976) and Rousseau (2006) for more]. As noted earlier, in the case of food defence the perception of threat is driven both by perceptions of vulnerability and events which make certain risks or fears more salient. 
Threat assessments can be wrong and naturally incomplete for a number of reasons: information may be incomplete, misleading, or ill-utilised based on the vagaries of an analyst's subjective assessments; organisational pressures, routines, and politics may distort the process of analysis (Betts, 1978; Cooper, 2005; Heuer, 1999; Laquer, 1985; Wirtz, 1991). However, since we are dealing in the realm of human agency it is important that we attempt an assessment of whether an attacker has the intent and capability to do what we fear they might. As noted above, a vulnerability assessment without the existence of human agency and the capacity to carry out that agency is too often subject to extensive imagination or assumption of success and/or failure on one's own part; imagination is useful for drawing up worst-case scenarios but on its own of little use in prioritising policy or resources properly. In the following sections, we explore the related concepts of capability and intentions in order to highlight how current assessments of food defence are deficient.

\subsection{Capability}

For the purpose of this article we take capability to be "a course of action or a faculty for development which lies within the capacity of the person or thing concerned" (Smith, 1956, 1995). There was some controversy during the Cold War period about measuring capability, specifically regarding whether it should be a measure solely focused on the types of weapons possessed, or whether it should also include organisational and operational resources, amongst others (Cragin and Daly, 2004; Garthoff, 1978, 2007; Gates, 1992, 1996; Kehm, 1956, 1995; Mandel, 2008; Stech, 1979).

In the case of food defence organisational and operational factors are vitally important. Such resources can be either material or non-material in nature (Handel, 1984), for example expert knowledge of the production of specific types of contaminants is non-material in nature but of importance in measuring the capability of an organisation's ability to implement a food defence incident. Jackson and Frelinger (2009, pp.8-11) provides a useful breakdown of separate, measurable components of capability such as: tools, situational awareness, number and quality of people available, technical skills, operational security skills, planning skills, command and control or leadership skills.

Too often measures of capability during the Cold War failed to differentiate between 'gross' capabilities and 'net' capabilities (Smith, 1995) wherein the former is capability without reference to concomitant capabilities of the defender's system to mitigate an action and the latter takes into account ones own capabilities. In this regard, perceptions of vulnerability are worth noting as a measure of one's confidence in defending or mitigating a perceived threat [Cohen, (1979), pp.103-104]. Capability is therefore relational. A thorough accounting of one's own capabilities might include (on the private side) safety and security systems for stopping, mitigating, detecting contaminants and individual(s) and (on the state's side) the capability of public services to deter, detect, mitigate or respond to adversary plans.

\subsection{Intentions}

There are a variety of ways in which intentions can be defined, the full scope of which is outside the bounds of this paper; Stech's monograph Political and Military Intention Estimation: A Taxonometric Analysis (1979) has a fuller, and much more philosophical, 
discussion on the variety of ways one can define intentions. For our purposes here we use Stech's (1979, p.16) definition of intention as "a decided-upon, planned future action, as distinct from prophecies, expectations, estimates, and the future actions themselves". Intentions can be seen, therefore, in a very basic sense as equivalent with future goals or plans. However, they do not simply exist in the mind of an individual (and, indeed, intentions that exist solely in the mind of an individual are not ones we can have any notion of worrying about), but have physical manifestations in the actions taken to meet expectations or goals.

There leads, however, to a tension in how we gauge intentions. If we see intentions purely as plans or future goals we tend to focus on how such desired outcomes are communicated, whether publicly or internally to group members. There is a particular class of terrorism literature which takes a sort of hermeneutical stance to terrorist organisations' public communications [for example see Scheuer (2003, 2007)]. This has a serious effect on our estimates of threat; by giving greater weight to public communication as solely the measure of an opponent's intentions, combined with vulnerability-driven assessments, we ignore the capability of an opponent to make their intentions manifest. Simply put, by ignoring capability we overestimate the ability to cause harm. Similarly, by simply analysing intentions we open an entire world of means by which an opponent can actualise such intentions, rather than focusing on by what means they have to do so (i.e., the capability they have to cause harm). And, in the case of terrorist groups, it seems their greatest capability is still within the rather traditional - and for food defence and bioterrorism proponents, rather staid - realm of bombs and bullets.

The public communication of terrorist organisations may indeed be one manner by which one can assesses intentions, but it must be remembered that communication is often strategic (Corman et al., 2008), designed with specific audiences in mind rather than merely an overt statement of their goals and plans (intentions). Such communications often can be persuasive in nature and serve ideological functions for a group, framing or justifying certain paths for action (Halverson et al., 2011). In that sense, while public communications serve an important function it may be more by nature post hoc rather than prescriptive.

Public communications may themselves be the result of an organisation's intentions in the form of propaganda or psychological warfare. This in itself may be of importance in how we react to terrorist organisational communication, as it may simply be an attempt on an adversary's part to gauge reactions. Rasmussen (2006) posits that different cultures have differing levels of tolerance to risk which an adversary may attempt to take advantage of for strategic purposes.

At the same time public communications, as well as knowledge gained from both successful and unsuccessful plots can be important sources of information for examining elements of an opponent's organisational decision-making (Garthoff, 1978; Stech and Hoffman, 1982). As Garthoff notes in an article on intelligence estimates, "it would be foolish to base our judgements only on what they say, and not also on what they do" [Garthoff, (1978), p.26]. It is here where the balance between capability and intentions comes into play as intentions themselves may in fact be limited by an opponent's resources, perception of risk, experience, and so on (Jackson and Frelinger, 2009; Schneier, 2006; Stech and Hoffman, 1982). The importance of focusing on intentions and capability is borne out by a study on success and failure in terrorist operations which found, not entirely surprisingly, that when there is a mismatch between intention and 
capability there is a higher likelihood of failure (Jackson and Frelinger, 2009). As such, in conjunction with assessing intentions we must also assess whether an opponent has the capability to carry out their intentions with a high degree of success.

\section{Re-examining the assumptions of food defence}

The current focus, especially in the realm of both food defence and chemical and biological terrorism, essentially treats biological and chemical agents as capabilities in and of themselves without any reference to whether such agents are actually possessed by an adversary. When we take such a view then all narratives of the future become worst-case scenarios (Rasmussen, 2006). Conversely, we may ignore capability and focus solely on intention, regardless of any adversary's capability to manifest such intention. In some cases, it appears, both capability and intention are ignored and instead one's own perception of vulnerability is seen as the threat. In this section, we re-examine the core assumptions of food defence within the context of capability and intentions.

\section{Assumption 1 There is a 'real and current threat' to the food supply chain from terrorists.}

The first assumption, upon which much of the foundation of food defence rests, is simply that terrorist organisations have the intent to attack the food supply chain. This is most clearly articulated in the 2002 WHO Report and the declassified 2003 FDA document quoted at the beginning of this paper. Material allegedly found in 2001 at the Tarnak Farms training camp in Afghanistan indicated an interest on the part of al-Qaeda in plant and animal diseases, doing little to dispel fears of such threats (Kennedy, 2007).

This threat perception, to reiterate an earlier point, can be seen as a result of the $9 / 11$ attacks and Amerithrax incidents, as well as perhaps a lingering hangover of 1990s-era bioterrorism fears. As we state earlier, the result of the strategic surprise of 9/11 meant that many possible threats were perceived as more likely. Former US Assistant Secretary for Arms Control Bohlen (2001) said, "The possibility that [biological weapons] might be used on a massive scale must now, after September 11, be regarded as less remote than before". A more recent Newsweek magazine article stated that, "The possibility that the nation's food supply could be targeted by terrorists has existed since at least the anthrax letters of October 2001" (Begley, 2007).

Given the extensive vulnerability-driven threat perception there is very little supporting evidence in open sources of terrorist organisations having either actual intent - or capability - to attack the food supply chain in order to cause mass casualties, whether with chemical or biological materials. As one FBI intelligence officer put it, "We sometimes focus on tactics that may be exotic and esoteric... but for most terrorists, they're looking for what works" [quoted in Jackson and Frelinger, (2009), p.1]. The US Department of Homeland Security (DHS) states (n.d.) "they lack credible information to indicate transnational terrorist planning for an attack against food and agriculture" on al Qaeda's part and note that the organisation is focused on "producing mass casualties, visually dramatic destruction, significant economic aftershocks, [and] fear amongst [the] U.S. population". Indeed, studies of terrorist targeting preferences and methods show that such organisations often attempt to keep operations as simple as possible, using known and largely reliable weapons, and are often constrained by funding issues (Libicki et al., 2007; Jackson and Frelinger, 2009; Schneier, 2006). 
Extremist training manuals commonly found online do contain references to the use of poisons, but only in the context of targeted assassinations, not mass poisonings using food as a delivery vehicle. The Central Intelligence Agency (CIA), in its unclassified reporting on terrorist groups' acquisition or interest in chemical and biological weapons, notes (2004) that such groups are mainly "focused on agents for use in small-scale poisonings or assassinations". This same report does note some interest in acquiring material to poison food or water although it is not exotic biological agents which most interests such organisations but "toxic industrial chemicals - most of which are relatively easy to acquire and handle" (CIA, 2004). This concurs with our previous research into food defence incidents (Dalziel, 2009) that the most commonly used compounds for poisonings were those that were either at hand or readily available for purchase. This is backed up by former US Director of National Intelligence (DNI) Blair's (2009) congressional testimony where he states, "Small-scale chemical attacks using industrial toxins have been the most frequent type of CBRN attack to date".

Chemical or, especially, biological agents themselves may lack the sort of "stability and predictability" [Alibek and Handelman, (1999), p.97] that a terrorist group may seek; the food supply chain only increases the uncertainty in the efficacy of a group's plot. A pre-9/11 GAO report states that:

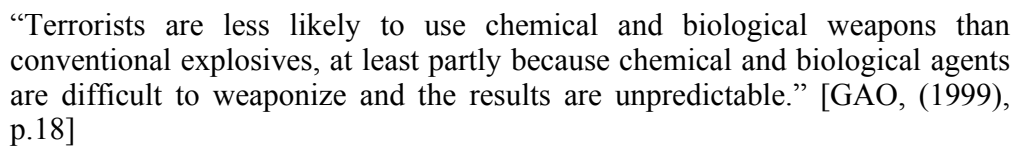

While the DNI's intelligence threat assessment testimony makes mention of the possible threat of contaminated food, it specifically includes both accidental and economic reasons for contamination, not terrorists as a threat to the US populace. Similarly, mentioned far more often is the threat of food security to US national interests (Blair, 2009, 2010).

Assumption 2 It is easy to carry out an attack on the food supply chain.

The food supply chain is often viewed as an easy target to attack and as an effective vehicle for causing mass harm to public health using biological or chemical agents. This perception is most clearly expressed in the fears expressed in US HHS Secretary Thompson's resignation speech, cited earlier. Under this assumption, if terrorists did have the intention to attack the food supply chain they could easily do so. The apparent ease in which the food supply chain can be attacked is either due to perceived vulnerabilities in the system which can be exploited and/or the ease in which terrorist organisations can manufacture or acquire biological or chemical materials. One paper even baldly states, "Deliberate food and water contamination remains the easiest way to distribute biological or chemical agents for the purpose of terrorism" [Khan et al., (2001), p.3].

Given the focus on the use of biological materials (with a lesser focus on chemical materials) food defence can usefully be viewed as a niche threat (Jackson and Frelinger, 2009), a subset of the larger bio-terrorism threat perception. Acquiring either the knowledge in how to make biological weapons, or the materials to do so, is often seen as fairly easy. A 2007 Newsweek article about food defence noted that "Suspects in last month's failed car bombings in London and Glasgow, for instance, include physicians, a reminder that terrorists can have biomedical know-how". This, of course, fails to explain why they chose to engage in attempting to use car bombs in London and Glasgow instead of leveraging their 'biomedical know-how'. 
Similarly, fears abound that even without the professional background of the aforementioned bombers manufacturing biological agents can be easily achieved without major financial investment and by using instructions found online (e.g., Danzig and Berkowsky, 1997). A competing assessment of the challenges of acquiring this sort of capability would argue that without the sort of resources most commonly held by a state it would be extremely difficult both to manufacture an effective biological or chemical agent and to deliver it successfully (e.g., Hinton, 1999). Indeed, recipes and instructions alone do not confer the sort of tacit knowledge (Vogel, 2006) and experience that is necessary to manufacture either chemical or biological agents, nor do recipes alone give one access to necessary equipment and materiel.

The utility of such publicly available sources of information on manufacturing biological agents is spurious as well. One technical analysis of the information contained in such manuals regarding poisons does not disregard the intent behind such information but derides the sort of capabilities that such information may lend an attacker: "Careful examination of the document shows that it is crammed with errors, seemingly the work of someone with little discernible sense, profoundly ignorant of the nature of simple compounds and incompetent in even minor [laboratory] procedures" (Stein, 2005). Leitenberg (2004, p.204), who has studied biological weapons since the 1960s, examined the manuals and wrote they "were crude to the point of being useless".

The apparent 'capability' amassed by Al Qaeda in this regard does not seem to match their assumed intent. Besides the near-useless training manuals, the 'materials' discovered in Afghanistan at the Tarnak Farms training camp were a collection of "journal articles themselves, as well as handbook excerpts on anthrax, plague, botulinum and so on" [Leitenberg, (2004), p.133]. Leitenberg also states that amongst the reference documents were ten pages of correspondence between an individual in the UK and someone in Afghanistan. His assessment (2004, p.134) is worth quoting in full:

\begin{abstract}
"What the documents indicate is an individual with PhD-level training, who understands the professional microbiology literature, who knows what he must do to obtain and export pathogen cultures in a proper fashion, who is willing to trade on the access provided by his status, while concealing the true purpose of his activities, which was to provide al-Qaeda with the means to attempt its first real BW production capability.... There is no evidence in any of these pages to indicate that any bacterial cultures had yet been obtained, or that any had been shipped to Afghanistan or Pakistan, or that any work had yet begun. In fact all the phrasing on these pages suggests that none of these things had yet occurred."
\end{abstract}

Assumption 3 The effects of the food defence threat can be extrapolated from food safety incidents.

The logic is that if such unintentional food safety contamination issues still occur, than determined individuals with malevolent intentions could replicate such negative effects. Indeed, a DHS report on food defence (2007, p.4) states:
"the prospect of a mass-scale food contamination event is of particular concern because the nation is subject to major unintentional foodborne illness outbreaks. Experts reason that ... an individual or individuals with malevolent aims could reproduce these outbreaks with dire consequences."

This same DHS report lists the variety of ways that food safety breakdowns (i.e., unintentional contamination) can impact public health, in order to underscore the 
potential impact a terrorist incident in this sector could have [Department of Homeland Security, (2007), pp.7-9]. Indeed, the impact of previous food safety incidents serve for many as vivid examples of the potential damage terrorists could attain via the food supply chain (Khan et al., 2001). Other food defence proponents state that "the potential results of an attack on the food supply can be inferred from examples of unintentional foodborne disease outbreaks" [Sobel et al., (2002), p.874]. Another writes, "naturally occurring outbreaks of diseases affecting livestock, as well as accidental contamination of food, further illustrate the potentially horrific effects of a deliberate and carefully choreographed event" [Dyckman, (2003), p.4]. Examples often given include Spain, 1981, where 20,000 injuries and 800 fatalities were caused by industrial rapeseed oil illegally added to consumer cooking oil, or in China, 1991, where 300,000 people contracted Hepatitis A from contaminated clams [Manning et al., (2005), p.107].

This type of thinking certainly fits into broader findings from research into the characteristics of particularly salient risks. Rohrmann and Renn (2000) noted that some qualitative risk characteristics that can increase the perception of risk include:

1 dread

2 familiarity

3 perception of control

4 potential to apportion responsibility for a situation.

In this sense, both food safety breakdowns and the food supply chain possess these risk characteristics. The sheer complexity of the modern, global food supply chain has increased uncertainty and decreased the perception of control over the safety of food stuffs.

However, the mere existence of unintentional food safety incidents causing harm to public health does not necessarily mean that malevolent actors can replicate such effects. As Jenkins noted in regards to the threat perception of nuclear terrorism, "there is no logical progression from truck bombs to nuclear bombs" (Kitfield, 2008). Similarly, there is no logical progression from the existence of unintentional incidents to intentional ones. It is a worrying leap, or lapse, in logic to conflate either unintentional incidents - or economically-motivated intentional incidents - with terrorism [one recent example of this is Hills, (2009)].

Instead of inferring from 'unintentional foodborne disease outbreaks' the results of an intentional attack for malicious purposes one might instead look at the results of actually occurring intentional attacks. The problem is that such attacks are incredibly rare, and rarely the type that food defence proponents envision (Dalziel, 2009). However, it is argued that, in the USA at least, 'foodborne bioterrorism' has occurred in the past and so therefore can occur again (Sobel et al., 2002). The three sole incidents of 'foodborne bioterrorism' in the USA given by Sobel et al. (2002), which appear often as examples throughout the food defence literature, do not seem to fit within the food defence paradigm (notwithstanding that one of the incidents occurred in Canada and not the USA).

The three examples par excellence are:

1 the 1984 Rajneeshee incident in which restaurant salad bars were contaminated with Salmonella Typhimurium (Török et al., 1997) 
2 a 1996 incident in the Dallas area where a laboratory worker sickened 12 of her colleagues with food intentionally contaminated with Shigella dystenteriae type 2 (Kolavic et al., 1997)

3 a 1970 incident where people in a Quebec home ate food contaminated with Ascaris suum (Phillis et al., 1972).

All three of these incidents occurred at the lower-end of the food supply chain, with only the Rajneeshee incident occurring at a food service node. The other two occurred in a workplace or home, not in a public setting. In all three cases those responsible for the incidents either had previous medical training or were working at the same time in medical research facilities with access to the materials at hand. While the Rajneeshee case saw a number of people sickened from eating at restaurants, none of the cases involved the type of worst-case scenario envisioned by food defence proponents of wide swathes of the public getting sickened from food contaminated at the top end of the food supply chain which is then propagated throughout the system.

Even if we extend our analysis to incidents occurring outside of the USA it is hard to find any incidents of the type that food defence proponents envision. Indeed, in our previous study of food defence incidents (Dalziel, 2009) we found that the deadliest incidents were ones that occurred at the retail-food service point of the supply chain, while the most common occurred in the home or workplace. The notion that food defence incidents should mirror food safety breakdowns obscures these findings.

More locally-targeted threat assessments may find there are, indeed, some anti-state groups that do have the intent to attempt actions against the food supply chain; and here we reiterate this may not be the type of poisonings often associated with the food defence literature. In addition to the trend in incidents explored in our previous study a separate database of terrorist incidents, the Global Terrorist Database, maintained by the University of Maryland contains 87,000 terrorist incidents collected between 1970 and 2008. Of these, 127 incidents are classified as targeting 'food or water supply'; however, 115 of these are some form of physical assault on an aspect of the food supply chain - such as delivery trucks - in areas that would commonly be classified as 'conflict zones' during a period of inter-state war, civil war, or insurgency. Such attacks may be deadly but hardly constitute the sort of direct threat to public health from poisoning that food defence envisions.

\section{Conclusions}

John J. Hamre, a former US Deputy Secretary of Defense, said in regards to the notorious 2002 National Intelligence Estimate on Iraqi Weapons of Mass Destruction (WMD) that the central concern of intelligence is an epistemological one with the key question being, "How do we know what we know, and how good is the information that comprises this knowledge?" [Bruce, (2008), p.171]. In the case of food defence much of our knowledge is framed by a vulnerability-driven perspective, focused on the effects of particular contaminants without reference to the intentions or capabilities of adversaries using such contaminants. The effect of this is a misperception in threat. As the terrorism scholar Jenkins (2003, p.14) has noted "there is a distance between ambition and achievement". That is, we must attempt to get a clear match between both intention (ambition) and capability (the greater the capability the improving odds of achievement). 
Open-source intelligence estimates by the US Government do not appear to support much of the assumptions of a terrorist threat to the food supply chain in the manner envisioned by food defence proponents. The main effect of focusing on the food supply chain as a vehicle for the dissemination of biological and chemical agents and equating food safety breakdowns with worst-case terrorism scenarios is that it obscures the fact that the most common occurrences of malicious intentional contamination occurs in the home or workplace. It also obscures the fact that the most harmful examples of such incidents occur at consumer points such as restaurants and cafeterias (see Dalziel, 2009). In fact, we found in our earlier study a total of 391 fatalities and 4,355 injuries over a period from 1950 until 2008; this is in contrast to the annual estimated 5,000 fatalities and 300,000 hospitalisations in the USA alone from foodborne illnesses and the almost 2 million annual deaths the WHO estimates from unsafe food and waterborne diseases [Dalziel, (2009), p.23].

In this paper, we have argued that the perceived threat which food defence is supposed to mitigate represents a vulnerability-driven approach that ignores fundamental questions of intention and capability. There is, we have argued in this paper, a basic misperception of threat in the case of food defence. This can obscure the actual and ongoing public health risk that food safety measures are designed to mitigate. Given the lack of any sort of (publicly-available) threat assessment in this domain supporting food defence, it remains a questionable assumption that there is intent on a terrorist organisation's part to utilise the food supply chain as a vehicle for disseminating harmful contaminants and that such a terrorist organisation would have the capability to do so successfully or effectively.

\section{References}

Ackerman, G.A. and Moran, K.S. (2004) 'Bioterrorism and threat assessment', Weapons of Mass Destruction Commission, Working paper No. 22.

Alibek, K. and Handelman, S. (1999) Biohazard: The Chilling True Story of the Largest Covert Biological Weapons Program in the World - Told from Inside by the Man Who Ran It, Random House, New York City.

Asia-Pacific Economic Cooperation (2006) 'APEC to increase protection of food supply from terrorist attack', (press release), 15 September 2006, available at http://www.apec.org/apec/news__media/2006_media_releases/150906_vn_cttf_foodsupply.h tml.

Ball-Rokeach, S.J. (1973) 'From pervasive ambiguity to a definition of the situation', Sociometry, Vol. 36, No. 3, pp.378-389.

Begley, S. (2007) 'Weaponizing hamburgers?', Newsweek, Vol. 150, No. 3, p.49.

Betts, R.K. (1978) 'Analysis, war, and decision: why intelligence failures are inevitable', World Politics, Vol. 31, No. 1, pp.61-89.

Betts, R.K. (2007) Enemies of Intelligence: Knowledge and Power in American National Security, Columbia University Press, New York.

Blair, D.C. (2009) 'Annual threat assessment of the intelligence community for the senate select committee on intelligence', Director of National Intelligence, 12 February 2009.

Blair, D.C. (2010) 'Annual threat assessment of the intelligence community for the senate select committee on intelligence', Director of National Intelligence, 2 February 2010. 
Bohlen, A.T. (2001) 'Statement in the first committee of the general assembly in general debate', United Nations, New York, available at

http://www.fas.org/programs/ssp/nukes/armscontrol/ga01bohlen.htm (accessed on 23 March 2011).

Branigan, W. et al. (2004) 'Tommy Thompson resigns from HHS', The Washington Post, 3 December.

Brodie, B. (1978) 'The development of nuclear strategy', International Security, Vol. 2, No. 4, pp.65-83.

Bruce, J.B. (2008) 'Making analysis more reliable: why epistemology matters to intelligence', in George, R.Z. and Bruce, J.B. (Eds.): Analyzing Intelligence: Origins, Obstacles, and Innovations, Georgetown University Press, Washington, DC.

Central Intelligence Agency (2004) 'Unclassified Report to Congress on the Acquisition of Technology Relating to Weapons of Mass Destruction and Advanced Conventional Munitions', 1 January-31 December 2004, available at http://www.cia.gov/library/reports/archived-reports-1/jan jun2001.htm\#18.

Cohen, R. (1979) Threat Perception in International Crisis, University of Wisconsin Press, Madison, WI.

Cooper, J.R. (2005) Curing Analytic Pathologies: Pathways to Improved Intelligence Analysis, Center for the Study of Intelligence, Washington, DC.

Corman, S., Tretheway, A. and Goodall, H.L. (Eds.) (2008) Weapons of Mass Persuasion: Strategic Communication to Combat Violent Extremism, Peter Lang, New York.

Cragin, K. and Daly, S.A. (2004) The Dynamic Terrorist Threat: An Assessment of Group Motivations and Capabilities in a Changing World, RAND, Washington, DC.

Dalziel, G.R. (2009) Food Defence Incidents 1950-2008: A Chronology and Analysis of Incidents Involving the Malicious Contamination of the Food Supply Chain, Centre of Excellence for National Security (CENS), S. Rajaratnam School of International Studies (RSIS), Nanyang Technological University (NTU), Singapore, available at http://www.rsis.edu.sg/cens/publications/reports/RSIS_Food\%20Defence_170209.pdf (accessed on 21 October 2010).

Danzig, R. and Berkowsky, P.B. (1997) 'Why should we be concerned about biological warfare?', JAMA, Vol. 278, No. 5, pp.431-432.

Department of Homeland Security (n.d) 'Homeland security threat overview', [Briefing], Office of Intelligence and Analysis.

Department of Homeland Security (2007) The Department of Homeland Security's Role in Food Defense and Critical Infrastructure Protection, Office of Inspector General, OIG-07-33.

Department of State (1975) 'Eighty-second meeting of the working group/cabinet committee to combat terrorism', Digital National Security Archive, Terrorism and U.S. Policy, 1968-2002 Collection, \#TE00400.

Dyckman, L.J. (2003) 'Bioterrorism: a threat to agriculture and the food supply', Testimony Before the Committee on Governmental Affairs, U.S. Senate, United States General Accounting Office, GAO-04-259T.

Fabi, R. (2003) 'FDA warns of "food terrorism"“, The Boston Globe, 11 October.

Garthoff, R.L. (1978) 'On estimating and imputing intentions', International Security, Vol. 2, No. 3, pp.22-32.

Garthoff, R.L. (2007) 'Estimating Soviet Military intentions and capabilities', in Haines, G.K. and Leggett, R.E. (Eds.): Watching the Bear: Essays on CIA's Analysis of the Soviet Union, Center for the Study of Intelligence, Washington, DC.

Gates, R.M. (1992, 1996) 'The prediction of Soviet intentions', Studies in Intelligence, Vol. 36, No. 5, pp.39-43.

Government Accountability Office (1999) Combating Terrorism: Need for Comprehensive Threat and Risk Assessments of Chemical and Biological Attacks, GAO/NSIAD-99-163. 
Handel, M.I. (1984) 'Intelligence and the problem of strategic surprise', Journal of Strategic Studies, Vol. 7, No. 3, pp.229-281.

Halverson, J.R., Goodall, H.L. Jr. and Corman, S.R. (2011) Master Narratives of Islamic Extremism, Palgrave Macmillan, New York.

Heuer, R.J. (1999) Psychology of Intelligence Analysis, Center for the Study of Intelligence, Washington, DC.

Hills, S. (2009) 'Food terrorism tops 2009 safety scare list', FoodProductionDaily.Com, 5 January, available at http://www.foodproductiondaily.com/Quality-Safety/Food-terrorism-tops-2009safety-scare-list (accessed on 22 October 2010).

Hinton, H.L. (1999) 'Combating terrorism: observations on the threat of chemical and biological terrorism', Testimony before the Subcommittee on National Security, Veterans Affairs, and International Relations, Committee on Government Reform, House of Representatives, GAO/T-NSIAD-00-50.

Hoffman, B. (2006) Inside Terrorism, Columbia University Press, New York.

Hope, B.K. (2004) 'Using fault tree analysis to assess bioterrorist risks to the U.S. food supply', Human and Ecological Risk Assessment: An International Journal, Vol. 10, No. 2, pp.327-347.

Hope, B.K. (2005) 'Risk assessment in bioterrorism', in Pilch, R.F. and Zilinskas, R.A. (Eds.): Encyclopedia of Bioterrorism Defense, Wiley-Liss, Hoboken, NJ.

Jackson, B.A. and Frelinger, D.R. (2009) Emerging Threats and Security Planning: How Should We Decide What Hypothetical Threats to Worry About?, RAND, Washington, DC.

Jenkins, B.M. (2003) Countering Al Qaeda: An Appreciation of the Situation and Suggestions for Strategy, RAND, Washington, DC.

Jervis, R. (1976) Perception and Misperception in International Politics, Princeton University Press, Princeton.

Kehm, H.D. (1956, 1995) 'Notes on some aspects of intelligence estimates', Studies in Intelligence, Vol. 1, No. 2, pp.19-37.

Kennedy, S. (2007) 'Identifying potential risks and preventing intentional contamination: the basics', Presentation at the 2007 Meat Industry Research Conference, 24 October, available at http://www.meatscience.org/Pubs/mircarchv/2007/MIRCKennedy.pdf (accessed on 20 October 2010).

Khan, A.S, Swerdlow, D.L. and Juranek, D.D. (2001) 'Precautions against biological and chemical terrorism directed at food and water supplies', Public Health Reports, Vol. 116, No. 1, pp.3-14.

Kitfield, J. (2008) 'Interview: how I learned not to fear the bomb', Global Security Newswire, 20 October, available at http://www.nti.org/d_newswire/issues/2008_10_20.html\#1D29B503 (accessed on 20 October 2010).

Kolavic, S.A. et al. (1997) 'An outbreak of Shigella dysenteriae type 2 among laboratory workers due to intentional food contamination', JAMA, Vol. 278, No. 5, pp.396-398.

Laquer, W. (1985) A World of Secrets: the Uses and Limits of Intelligence, Basic Books, New York.

Laquer, W. (2000) The New Terrorism: Fanaticism and the Arms of Mass Destruction, Oxford University Press, New York.

Lesser, I.O. et al. (1995) Countering the New Terrorism, RAND, Washington, DC.

Leitenberg, M. (2004) The Problem of Biological Weapons, The Swedish National Defence College, Stockholm.

Libicki, M.C., Chalk, P. and Sisson, M. (2007) Exploring Terrorist Targeting Preferences, RAND, Washington, DC.

Liu, Y. and Wein, L.M. (2008) 'Mathematically assessing the consequences of food terrorism scenarios', Journal of Food Science, Vol. 73, No. 7, pp.346-353. 
Mandel, R. (2008) Global Threat: Target-Centered Assessment and Management, Praeger Security International, Westport, CT.

Manning, L. et al. (2005) 'Deliberate contamination of the food supply chain', British Food Journal, Vol. 107, No. 4, pp.225-245.

Miller, J. (1986) 'A report to NATO paints a dark portrait', New York Times, 14 November.

Phillis, J.A. et al. (1972) 'Pulmonary infiltrates, asthma and eosinophilia due to Ascaris suum infestation in man', New England Journal of Medicine, Vol. 286, No. 18, pp.965-970.

Ramakrishna, K. and Tan, S.S. (Eds.) (2003) After Bali: The Threat of Terrorism in Southeast Asia, World Scientific Publishing, Singapore.

Rapoport, D.C. (2001) 'The fourth wave: September 11 in the history of terrorism', Current History, Vol. 100, No. 650, pp.419-424.

Rasmussen, M.V. (2006) The Risk Society at War: Terror, Technology and Strategy in the Twenty-First Century, Cambridge University Press, Cambridge, UK.

Rohrmann, B. and Renn, O. (2000) 'Risk perception research - an introduction', in Rohrmann, B. and Renn, O. (Eds.): Cross-Cultural Risk Perception: A Survey of Empirical Studies, Kluwer Academic Publishers, Norwell, MA.

Rose, G. (1999) 'It could happen here: facing the new terrorism', Foreign Affairs, Vol. 78, No. 2, pp.131-137.

Rousseau, D. (2006) Identifying Threats and Threatening Identities: The Social Construction of Realism and Liberalism, Stanford University Press, Stanford, CA.

Scheuer, M. (2003) Through our Enemies' Eyes: Osama Bin Laden, Radical Islam \& the Future of America, Potomac Books, Washington, DC.

Scheuer, M. (2007) Imperial Hubris: Why the West is Losing the War on Terror, Potomac Books, Washington, DC.

Schneier, B. (2006) Beyond Fear: Thinking Sensibly about Security in an Uncertain World, Springer, USA.

Simon, J.D. (1989) 'Terrorism and the potential use of biological weapons: a discussion of possibilities', Report: R-3771-AFMIC, RAND, Washington, DC.

Simon, S. and Benjamin, D. (2000) 'America and the new terrorism', Survival, Vol. 42, No. 1, pp.59-75.

Smith, A.E. (1956, 1995) 'Notes on "capabilities" in national intelligence', Studies in Intelligence, Vol. 1, No. 2, pp.1-18.

Sobel, J. (2005) 'Food and beverage sabotage', in Pilch, R.F. and Zilinskas, R.A. (Eds.): Encyclopedia of Bioterrorism Defense, Wiley-Liss, Hoboken, NJ.

Sobel, J., Khan, A.S. and Swerdlow, D.L. (2002) 'Threat of a biological attack on the US food supply: the CDC perspective', Lancet, Vol. 359, No. 9309, pp.874-880.

Stech, F.J. (1979) Political and Military Intention Estimation: A Taxonometric Analysis, Office of Naval Research.

Stech, F.J. and Hoffman, K.C. (1982) Methods of Estimating Strategic Intentions, Office of Naval Research.

Stein, J. (2005) 'Chemist derides Qaeda Germwar skills touted by manual', Congressional Quarterly, 8 August, available at http://www.globalsecurity.org/org/news/2005/050808-qaedagermwar.htm (accessed on 24 July 2011).

Török et al. (1997), 'A Large community outbreak of Salmonellosis caused by intentional contamination of restaurant salad bars', JAMA, Vol. 278, No. 5, pp.389-395.

Vogel, K. (2006) 'Bioweapons proliferation: where science studies and public policy collide', Social Studies of Science, Vol. 36, No. 5, pp.659-690.

Warrick, J. (2005) 'Media and bioterrorism', in Pilch, R.F. and Zilinskas, R.A. (Eds.): Encyclopedia of Bioterrorism Defense, Wiley-Liss, Hoboken, NJ. 
Wirtz, J.J. (1991) The Tet Offensive: Intelligence Failure in War, Cornell University Press, Ithaca, NY.

World Health Organization (2002) Terrorist Threats to Food: Guidance for Establishing and Strengthening Prevention and Response Systems, available at http://www.who.int/foodsafety/publications/general/en/terrorist.pdf (accessed on 23 October 2010).

\section{Notes}

1 Portions of this paper build on and are adapted from the author's previous work Food Defence Incidents 1950 to 2008: A Chronology and Analysis of Incidents Involving the Malicious Contamination of the Food Supply Chain, which was published as a report by the Centre of Excellence for National Security (CENS), S. Rajaratnam School of International Studies (RSIS), Nanyang Technological University (NTU), Singapore. That research was conducted while the author was an Associate Research Fellow at the CENS. Part of this food defence research project included a workshop conducted in Singapore, 16 February 2009 by CENS with the assistance of the National Security Coordination Secretariat (NSCS). More information can be found at the CENS website: http://www.rsis.edu.sg/cens/index.htm. The author is grateful to the two anonymous reviewers of this article, as well as comments and feedback on this and previous versions of this paper by: Richard Bitzinger, Bill Durode, Clint Lorimore, Ng Sue Chia, Kumar Ramakrishna, Motohiro Tsuchiya, and Norman Vasu. The author would also like to thank Deborah Kelley-Millburn for archival assistance with tracking down old references and Milton Leitenberg for his generous insight on some matters, and for mailing with great haste books and articles that were extremely useful. The views presented in this paper are the author's own and not those of any of the aforementioned institutions and any errors are his alone. 